\title{
Antioxidant, antimicrobial and phytotoxic activities of Rhaponticum acaule DC. essential oil
}

\author{
Habib Mosbah ${ }^{1^{*}}$, Ahlem Ben Sassi ${ }^{\circledR 2}$, Hassiba Chahdoura ${ }^{1}$, \\ Mejdi Snoussi $^{3}$, Guido Flamini ${ }^{4,5}$, Lotfi Achour', Boulbaba Selmi ${ }^{1}$ \\ ${ }^{1}$ Laboratory of Bioresources: Integrative Biology and Valorization, Higher Institute of Biotechnology \\ of Monastir, Monastir, Tunisia, ${ }^{2}$ Laboratory of Transmissible Diseases and Biological Active \\ Substances, Faculty of Pharmacy, Monastir, University of Monastir, Tunisia, ${ }^{3}$ Laboratory of Genetic, \\ Biodiversity and Valorization of Bioesources, Higher Institute of Biotechnology of Monastir, Monastir, \\ Tunisia, ${ }^{4}$ Dipartimento di Farmacia, Università di Pisa, Pisa, Italy, ${ }^{5}$ Centro Interdipartimentale \\ di Ricerca "Nutraceutica e Alimentazione per la Salute",Università di Pisa, Pisa, Italy
}

\begin{abstract}
The in-vitro antioxidant activity of Rhaponticum acaule essential oil (RaEO) was evaluated using $\beta$-carotene/linoleic acid bleaching, chelating activity, and lipid peroxidation inhibition (TBARS) assays. The antimicrobial activity of RaEO was assessed by disc diffusion and microdilution methods against 8 bacteria and 4 yeast. Finally, the allelopathic activity of RaEO on the seed germination and the shoot and root elongation of lettuce (Lactuca sativa L.) seedlings were investigated. According to our results, the RaEO exhibited significant antioxidant activity, similar to those of standards (BHT and ascorbic acid) with $\mathrm{IC}_{50}$ values of 0.042 and $0.045 \mathrm{mg} / \mathrm{mL}$ obtained by $\beta$-carotene bleaching and TBARS assays, respectively. On the other hand, despite its interesting ferrous chelating activity, RaEO possesses moderate $\mathrm{IC}_{50}$ value $(0.35 \mathrm{mg} / \mathrm{mL})$ as compared with that of EDTA $(0.015 \mathrm{mg} / \mathrm{mL})$. RaEO exhibited a strong antimicrobial activity against all the tested microorganisms, with IZ, MIC and $\mathrm{MBC}$ values being in the range of $7.67 \pm 0.58$ to $13.33 \pm 0.58 \mathrm{~mm}, 1.25$ to 5.00 and 5.00 to $10.00 \mathrm{mg} / \mathrm{mL}$, respectively. The results reveled also that RaEO inhibited the shoot and root growth of Lactuca sativa L. seedlings. Our data suggested that the RaEO had pharmaceutical benefits and could be used as a potential natural herbicide resource.
\end{abstract}

Keywords: Rhaponticum acaule essential oil. Antioxidant activity. Antimicrobial activity. Allelopathic activity.

\section{INTRODUCTION}

Currently, although many synthetic drugs are produced, they may exhibit some side effects as well as toxic properties to human health (Zhang, Sun, Wang, 2013; Hyun, Kim, Kim, 2014). Consequently, the use of natural compounds instead of synthetic ones might be desirable, and the separation of new natural compounds is of considerable interest. In fact, natural compounds are known for being attractive due to their low cost,

*Correspondence: H. Mosbah, Higher Institute of Biotechnology of Monastir, Avenue Taher Hadded BP, 74, 5000, Monastir, Tunisia. Tel: +216 73463374/Fax:+216 73465404. E-mail:mosbah_habib@yahoo.fr availability in large quantities from the raw material, biodegradability and general safety for human health and environment (Kong et al., 2010).

Amongst plant natural products, essential oils (EOs) have received important attention for their wide acceptance by consumers and their exploitation for multi-purpose use (Bakkaliet al., 2008). EOs are known as complex mixtures of secondary metabolites, produced by aromatic plants and characterized by their intense odors. They contain several types of chemicals, most of which consist of low-molecular-weight monoand sesquiterpenes. EOs are considered as good food additives. In fact, they increase the shelf-life of foods by minimizing rancidity and reducing the accumulation 
of toxic oxidation products (Kelen, Tepe 2008). Indeed, EOs can act as antioxidants due to their redox properties, which play an important role in adsorbing and neutralizing free radicals, or by decomposing peroxides, quenching singlet and triplet oxygen, or by chelating metal ions (Sarikurkcu et al., 2010).

Rhaponticum acaule DC. also known as Leuzea acaulis L. or Centaurea chamaerhaponticum Ball., is one of the most conspicuous aromatic plants of earlier spring flowering from January to March. It is a monospecific genus that belongs to the asteraceae family. It grows wild in rosette on the slopes of the hills, fields and in sandy pastures. $R$. acaule is a fragrant and perennial herb with yellow flowers and large and pinnatisect leaves. The capitula are big with fleshy and hairy receptacles. They are North African endemic species distributed in the north and central area of Tunisia (Pottier-Alapetite, 1981). In previous study, the chemical composition of $\mathrm{R}$ acaule aerial part essential oil was established and its inhibitory effect against xanthine oxidase, $\alpha$-glucosidase, and pancreatic lipase was also evaluated to explain the mechanism of inhibition applied by the compounds of this essential oil (Mosbah et al., 2018). As a continuation of this previous study conducted by our research group, the aim of the present study was to investigate, for the first time, the antioxidant, antimicrobial and allelopathic activities of RaEO.

\section{MATERIAL AND METHODS}

\section{Chemicals reagents}

Thiobarbituric acid (TBA), trichloroacetic acid (TCA), iron (II) sulfate (FeSO4), $\beta$-carotene, linoleic acid, hydrochloric acid ( $\mathrm{HCl})$, Ferrozine and ethylenediaminetetraacetic acid (EDTA) were purchased from Sigma-Aldrich. $\mathrm{NaCl}$ was obtained from (CHEMI PHARMA, Tunisia). Chloroform and methanol were purchased from Merck (Darmstadt, Germany). All solvents and reagents were used in the highest purity.

\section{Plant material and essential oil extraction}

The plants were collected at the flowering stage in January 2015 in the M'Saken (Sousse) area. The plant material was identified by Prof. Fethia Harzallah Skhiri (High Institute of Biotechnology of Monastir, Tunisia). A voucher specimen $\left(\mathrm{N}^{\circ} \cdot\right.$ Ra15) has been deposited in the Herbarium of the Laboratory of Bioressources: Biologie Integrative and Valorization, High Institute of Biotechnology of Monastir, University of Monastir, Tunisia.

The inflorescences freshly collected of $R$. acaule were cut in small pieces and thereafter submitted to hydrodistillation using a Clevenger-type apparatus as previously described. The obtained total yield of the volatile fraction was $0.018 \%(\mathrm{w} / \mathrm{w})$ (Mosbah et al., 2018).

\section{Antioxidant activity}

The RaEO was subjected to screening for their possible antioxidant activity using three colorimetric methods: $\beta$-carotene bleaching, ferrous ions chelating and TBARS assays. The obtained results were then compared to the standard products, butylated hydroxyl toluene (BHT), EDTA and ascorbic acid, respectively. The findings are expressed as EC50 values (i.e. the concentration at which the compound provided $50 \%$ inhibition).

\section{$\beta$-carotene bleaching assay}

The capacity of RaEO to inhibit the bleaching of $\beta$-carotene was assessed as previously described by Condelli et al. (2015) with minor modifications. In the first step, $5 \mathrm{mg}$ of $\beta$-carotene was dissolved in $10 \mathrm{~mL}$ of chloroform. $750 \mu \mathrm{L}$ of the obtained $\beta$-carotene solution, $33 \mu \mathrm{L}$ of linoliec acid and $225 \mathrm{mg}$ of Tween 40 were carefully mixed. Then, the solvent was removed using a rotary evaporator. To create an emulsion, water $(75 \mathrm{~mL})$ was slowly added to the mixture and vigorously agitated. Aliquots $(4 \mathrm{~mL})$ of the emulsion (freshly prepared before each experiment) were transferred into test tubes containing $200 \mu \mathrm{L}$ of RaEO serially diluted in methanol to produce a concentration ranging from $0.03 \mathrm{mg} / \mathrm{mL}$ to $1 \mathrm{mg} / \mathrm{mL}$. Thereafter, the tubes were incubated at $50{ }^{\circ} \mathrm{C}$ in a water bath for $2 \mathrm{~h}$ together with a negative control (blank), which contains the same volume of methanol, instead of the sample. The absorbance was measured for all samples at $470 \mathrm{~nm}$, immediately $(\mathrm{t}=0)$ and at after time of $120 \mathrm{~min}$, using a spectrophotometer against a blank composed by emulsion without $\beta$-carotene. The percentage inhibition was calculated using the following formula:

$\mathrm{I} \%=\left(\mathrm{AS}_{120 \min }-\mathrm{AC}_{120 \min } / \mathrm{AC}_{0 \min }-\mathrm{AC}_{120 \min }\right) \times 100 \%$ 
Where $\mathrm{AS}_{120 \min }$ is the absorbance of the sample at $\mathrm{t}=$ $120 \mathrm{~min}, \mathrm{AC}_{120 \mathrm{~min}}$ is the absorbance of the control at $\mathrm{t}=120 \mathrm{~min}$, and $\mathrm{AC}_{0 \text { min }}$ is the absorbance of the control at $\mathrm{t}=0 \mathrm{~min}$.

Samples were read using a blank containing the emulsion of $\beta$-carotene/linoleic acid. Essential oil concentration $(\mathrm{mg} / \mathrm{mL})$, which corresponds to $50 \%$ of inhibition (EC50), was calculated from the graph plotting antioxidant activity against essential oil concentration. Butylated hydroxyl toluene (BHT) was used as a positive standard. All the tests were carried out for three sample replications and the results were averaged.

\section{Ferrous ions chelating assay}

The iron-chelating capacity of the essential oil was assessed according to the method of Zhu et al. (2006) with minor modifications. For each test, $100 \mu \mathrm{L}$ of essential oil dissolved in methanol at different concentrations varying between $0.03 \mathrm{mg} / \mathrm{mL}$ and $1 \mathrm{mg} /$ $\mathrm{mL}$ were added to $50 \mu \mathrm{L}$ of FeSO4 $(2 \mathrm{mM})$. Thereafter, the mixtures were incubated at room temperature for 5 min followed by the addition of $100 \mu \mathrm{L}$ of ferrozine solution $(5 \mathrm{mM})$ to trigger the reaction. Finally, the test tubes were then shaken and left to stand at room temperature for $10 \mathrm{~min}$. Similarly, control tubes were prepared, with the substitution of the essential oil by methanol. EDTA was used as a positive control. The absorbance of solutions was measured at $562 \mathrm{~nm}$, and the chelating activity (\%) was calculated as follows:

Metal chelating activity $(\mathbf{\%})=[(\mathrm{ODC}+\mathrm{ODB}-\mathrm{ODS}) /$ ODC] $\times 100$,

where ODC, ODB and ODS represent the absorbances of the control, the blank and the sample reaction tubes, respectively.

\section{Thiobarbituric acid reactive species (TBARS) assay}

The inhibition power of lipid peroxidation products was carried out using thiobarbituric acid reactive substance (TBARS) quantification in homogenized sheep brain samples as described by Bellé et al. (2004) with minor modifications. The sheep brain was dissected, homogenized with a Polytron in ice cold Tris- $\mathrm{HCl}$ buffer (20 mM, pH 7.4) and was centrifuged at $3000 \mathrm{~g}$ forl0 min. An aliquot $(100 \mu \mathrm{L})$ of the supernatant was incubated at $37^{\circ} \mathrm{C}$ for $1 \mathrm{~h}$ with $200 \mu \mathrm{L}$ from each sample concentration in the presence of $100 \mu \mathrm{L}$ FeSO4 (10 $\mathrm{mM})$ and $100 \mu \mathrm{L}$ ascorbic acid $(0.1 \mathrm{mM})$. The reaction was stopped by the addition of $500 \mu \mathrm{L}$ trichloroacetic acid $(28 \% \mathrm{w} / \mathrm{v})$, followed by $380 \mu \mathrm{L}$ thiobarbituric acid (TBA, 2\%,w/v), and the mixture was then heated at $80{ }^{\circ} \mathrm{C}$ for $20 \mathrm{~min}$. After centrifugation at $3000 \mathrm{~g}$ for 10 min to remove the precipitated protein, the color intensity of the malondialdehyde (MDA)-TBA complex in the supernatant was measured at $532 \mathrm{~nm}$. The inhibition ratio (\%) was calculated using the following formula:

Inhibition ratio $(\%)=\left[\left(\mathrm{Abs}_{\mathrm{C}}-\mathrm{Abs}_{\mathrm{S}}\right) / \mathrm{Abs}_{\mathrm{C}}\right] \times 100 \%$,

where $\mathrm{Abs}_{\mathrm{C}}$ and $\mathrm{Abs}_{\mathrm{S}}$ were the absorbance of the control and the sample solution, respectively.

\section{Antimicrobial activity}

\section{Microorganisms}

The test microorganisms included the following Gram-positive bacteria: Staphylococcus aureus ATCC 6816, Staphylococcus epidermidis CECT 231, and Gram negative bacteria: Pseudomonas aeruginosa PAO1, Salmonella enterica subsp. enterica CECT 443, Listeria monocytogenes CECT 933, Vibrio parahaemolyticus ATCC 43996, Vibrio parahaemolyticus CECT 511, Vibrio vulnificus CECT 529. On the other hand, the antifungal effect was tested against four Candida strains (C.albicans ATCC 2091, C. parapsilosis ATCC 22019, C. glabrata ATCC90030, and C. tropicalis 06-085).

\section{Disc-diffusion assay}

The test of antimicrobial activity was done according to the protocol described by Vuddhakul et al. (2007) with same modifications. For the experiments, $10 \mu \mathrm{L}$ of the microorganisms working stocks were enriched on a tube containing $9 \mathrm{~mL}$ of Mueller-Hinton (MH) broth (for bacteria) and Sabouraud (SB) Chloramphenicol broth (for Candida), then incubated at $37^{\circ} \mathrm{C}$ for $24 \mathrm{~h}$. After one night, the cultures were used for the antimicrobial activity of the essential oil and the optical density was adjusted to $10^{7}$ to $10^{8} \mathrm{CFU} / \mathrm{mL}$ (0.1 at OD600 for bacteria and 0.4 at OD540 for Candida strains). The inoculums of the respective bacteria and fungus were streaked onto $\mathrm{MH}$ or SB agar plates using a sterile cotton swab as recommended by the CA-SFM EUCAST 2017. sterile filter discs (diameter $6 \mathrm{~mm}$, Biolife Italy) were 
impregnated with $10 \mu \mathrm{L}$ of essential oil $(20 \mathrm{mg} / \mathrm{mL})$ placed on the appropriate agar mediums. Ampicillin (10 $\mathrm{mg} / \mathrm{mL} ; 10 \mu \mathrm{L} / \mathrm{disc})$ and Amphotericin B $(10 \mathrm{mg} / \mathrm{mL}$; $10 \mu \mathrm{L} /$ disc) were used as positive reference standards.

After $24 \mathrm{~h}$ of incubation at $37^{\circ} \mathrm{C}$, the diameter $(\mathrm{mm})$ of the growth inhibition zone (IZ) was measured. Each experiment was performed in triplicate and the mean diameter of the inhibition zone was recorded. The results were expressed in terms of inhibition zone (IZ) of growth around each disc in millimeters as low activity $(1-6 \mathrm{~mm})$, moderate activity $(7-10 \mathrm{~mm})$, high activity $(11-15 \mathrm{~mm})$ and very high activity $(12-20 \mathrm{~mm})$ (Parveen et al., 2010).

\section{Micro-well determination of MICs and MBCs/MFCs}

The minimal inhibition concentrations (MICs) and the minimal bactericidal/fungicidal concentrations (MBCs/MFCs) values were determined for all bacterial/ fungal strains used in this study as described by Snoussi et al. (2015) with minor modifications. The bacterial/ fungal inoculums were prepared from $12 \mathrm{~h}$ broth cultures, and suspensions were spectrophotometrically adjusted to $107 \mathrm{CFU} / \mathrm{mL}$. The RaEO was first dissolved in 10\% dimethylsulfoxide (DMSO). Then, serial twofold dilutions were made in a concentration ranging from 0.008 to $20 \mathrm{mg} / \mathrm{mL}$ in $5 \mathrm{~mL}$ sterile glass tubes containing nutrient broth. The plates were prepared by adding $95 \mu \mathrm{L}$ of nutrient broth and $100 \mu \mathrm{L}$ of stock solutions of essential oil, respectively, into each well. Finally, 5 $\mu \mathrm{L}$ from each microbial suspension were added to all wells. The first well of each plate contained $195 \mu \mathrm{L}$ of nutrient broth (Mueller Hinton broth or Sabouraud Chloramphenicol broth) without essential oil, and $5 \mu \mathrm{L}$ of the inoculum was used as a negative control. The final volume in each well was $200 \mu \mathrm{L}$. The plates were, thereafter, incubated at $37^{\circ} \mathrm{C}$ during $24 \mathrm{~h}$. The MIC was defined as the lowest concentration of RaEO to inhibit the growth of the microorganisms. Consequently, no visible changes were detected in the broth medium. On the other hand, the $\mathrm{MBC} / \mathrm{MFC}$ values were recorded as the lowest concentration of the essential oil, which resulted in a clear fluid with no visible growth. All tests were assessed in triplicate.

\section{Phytotoxicity assay}

The inhibition potential of RaEO on the seed germination as well as the shoot and root elongation of lettuce (Lactuca sativa L.) seedlings were investigated. Lettuce seeds were purchased from a seed shop, disinfected for $5 \mathrm{~min}$ with $\mathrm{NaCl}(1 \%)$, and then rinsed with dist. H2O (Mabrouk et al., 2013). Three replicates, each comprising 20 seeds, were prepared for the contact tests with the essential oil, using sterile Petri dishes $(90 \mathrm{~mm}$ diameter) lined with double-sterile filter paper (Whatman No. 2). The essential oil was dispersed as an emulsion in dist. H2O using Tween 20. Four doses of the essential oil $(0.01,0.05,0.1$, and $0.25 \mathrm{mg} / \mathrm{mL})$ were obtained by the dilution of the emulsion with deionized $\mathrm{H} 2 \mathrm{O}$. The dishes were then moistened with $5 \mathrm{~mL}$ of essential oil at different concentrations or with $5 \mathrm{~mL}$ of dist. $\mathrm{H} 2 \mathrm{O}$, used as a negative control. Thereafter, the dishes were sealed with Parafilm, to prevent the loss of moisture and to avoid contamination, and placed in a growth chamber to allow germination in the dark at an average temperature of 23 $\pm 2{ }^{\circ} \mathrm{C}$ for 7 days. As a result, the seed was considered germinated when the protrusion of the radicle became evident (Mabrouk et al., 2013). Tests were assessed in triplicate for each treatment and control. After 7 days, the germination percentage was determined. Then, the seedlings of L. sativa were collected and the length of each shoot and root was measured to evaluate the allelopathic activity of the RaEO. The inhibitory or stimulatory effects were calculated using the following equation, with slight modifications as described by Chung, Ahn and Yun (2001):

Inhibition $(-) /$ stimulation $(+) \%=((\mathrm{EOe}-\mathrm{Ce}) / \mathrm{Ce}) \times 100$

where EOe (essential oil effect) is the parameter measured in the presence of essential oil and Ce (control effect) is the parameter measured in the presence of dist. $\mathrm{H} 2 \mathrm{O}$.

\section{Statistical analysis}

Each assay was performed in triplicate. Results were expressed as the mean values \pm standard deviation $(\mathrm{n}=3)$. The differences were calculated using oneway analysis of variance (ANOVA) and statistically significant differences were reported at $\mathrm{p}<0.05$. Data analyses were carried out using the SPSS 10.0 software.

\section{RESULTS AND DISCUSSION}

\section{Antioxidant activity}


To the best of our knowledge, this is the first study on the antioxidant effectiveness of RaEO. Firstly, the antioxidant activity of RaEO was measured by the $\beta$-carotene-linoleate system and compared with that of BHT used as a positive control (Figure 1). The results indicate that $\mathrm{RaEO}$ prevented the bleaching of $\beta$-carotene with an effectiveness similar to that of BHT at all the tested concentrations. The antioxidant activity values for the essential oil and BHT (both at $1 \mathrm{mg} / \mathrm{mL}$ ) were found to be $82.4 \%$ and $84.5 \%$, respectively.

As a second method, the $\mathrm{Fe}^{2+}$ chelation was used to evaluate the ability of RaEO in metal-chelating activity. Mixing ferrozine with the $\mathrm{Fe}^{2+}$ ion forms complexes, that are disrupted in the presence of chelating agents, resulted, subsequently, in a decrease in color formation (Thiansilakul, Benjakul, Shahidi, 2007). Ferrous chelating activities of RaEO at different concentrations are shown in Figure2. The results indicated that this oil was able to chelate the $\mathrm{Fe}^{2+}$ ion with dose dependent effect. Despite its interesting ferrous chelating activity, RaEO possesses a moderate EC50 value $(0.35 \mathrm{mg} / \mathrm{mL})$ compared with that of EDTA $(0.015 \mathrm{mg} / \mathrm{mL})$ used as a positive control.

The TBARS method is considered to be one of the best approaches to evaluate the real antioxidant behavior in foods. It is well known that lipid peroxidation is caused by the generation of free radicals from several sources including organic hydroperoxides, iron-containing compounds and redox cycling compounds. The TBARS test has been used to measure the lipid peroxidation degree. TBA reacts specifically with malondialdehyde (MDA), a secondary product of lipid peroxidation to give a red chromogen, which may be subsequently measured spectrophotometrically (Coppen, 1983). The percentage of lipid peroxidation inhibition of the essential oil and the synthetic antioxidant generally used in food industry (ascorbic acid) is summarized in Figure 3. RaEO and ascorbic acid showed similar lipid antioxidant activity at all the tested concentrations, with the same EC50 value of about $0.04 \mathrm{mg} / \mathrm{mL}$.

To correlate the obtained results of antioxidant activity with the chemical composition of the RaEO, it is interesting to refer to the paper of Ruberto and Baratta (2000). The latter studied the antioxidant activity of 98 pure essential oil components, which represent the main class of typical compounds contained in essential oils. They reported that sesquiterpene hydrocarbons displayed a low scavenging activity, whereas monoterpene hydrocarbons exhibited a significant protective effect, with several variants due to their different functional groups. Indeed, according to the literature, the scavenging mechanism of sesquiterpenes may be due to the abstraction of a hydrogen atom from a methylene group (-CH2-) on the sesquiterpenes to form an allyl radical (Priyadarsini et al., 2003). Moreover, the allyl radical of the carbon radical tends to be stabilized by a molecular rearrangement or by the abstraction of a hydrogen atom from another methylene group to form a conjugated diene or other stable compounds (Espin, Soler-Rivas, Wichers, 2000). However, antioxidant activities were also reported for various essential oils isolated from other plants that belong to the asteraceae family (Laciar et al., 2009; Sokmen et al., 2004; Yayli et al., 2005; Matasyoh et al., 2007; Silvério et al., 2013). Probably, similar components detected in our essential oil could be responsible for these properties, such as germacrene $\mathrm{D}$ and $\beta$-caryophyllene (Matasyoh et al., 2007). The antioxidant activity observed for RaEO could be attributed to the presence of high percentages of germacrene D (49.2\%), methyl eugenol (8.3\%) and $\beta$-caryophyllene (5.7\%) (Mosbah et al., 2018).

Essentially, it can be noted that the essential oils are quite complex mixtures, constituted by several tens of components. This complexity makes it often difficult to explain the activity pattern. For this reason, in many reports, the antioxidant potentials of essential oils are explained by specific concepts such as synergism, antagonism and additivity.

According to the literature, the asteraceae species are well documented as natural antioxidants (Maisuthisakul, Suttajit, Pongsawatmanit, 2007) but to the best of our knowledge, this is the first work performed on the essential oil of $R$. acaule. 


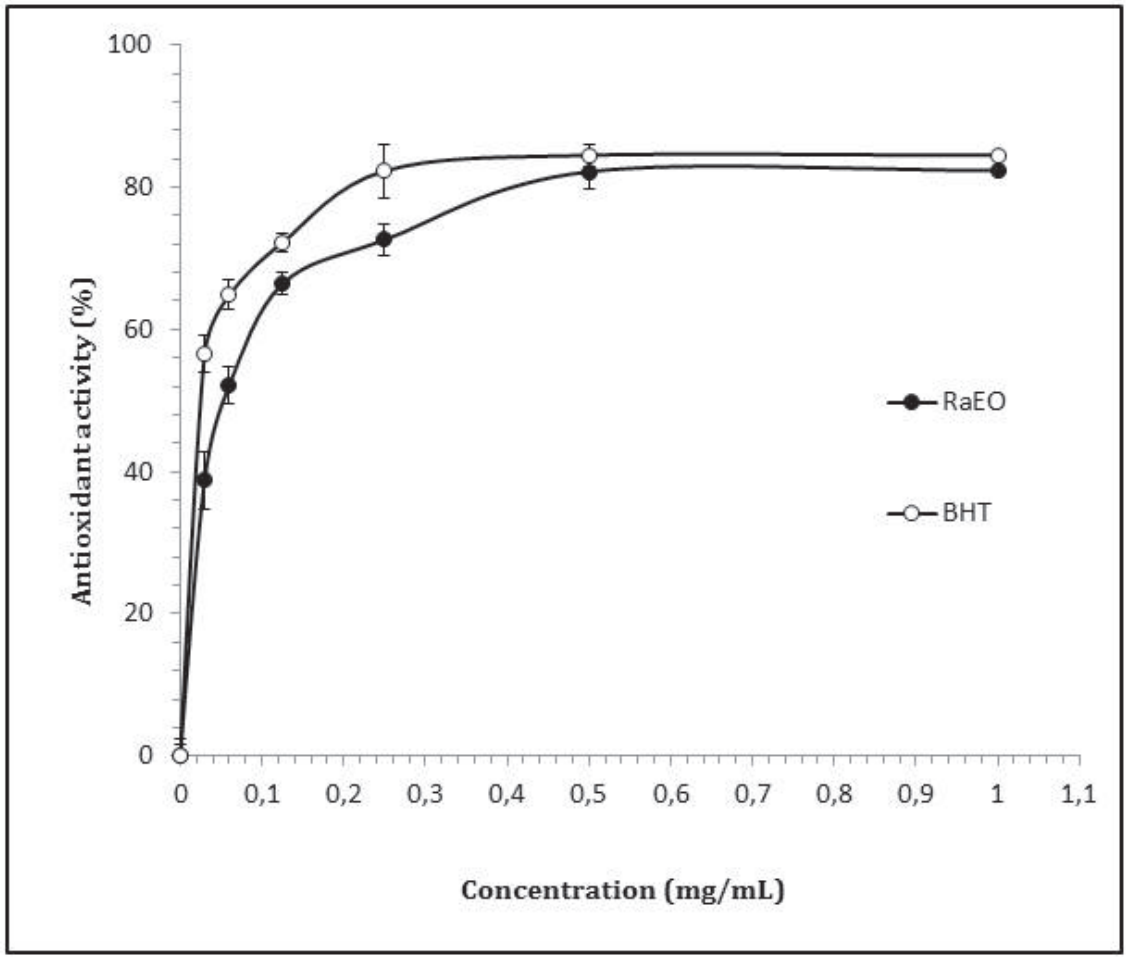

FIGURE 1 - Antioxidant activity of RaEO using $\beta$-carotene bleaching method. BHT was used as positive control. Data represent the mean $( \pm \mathrm{SD})$ of three independent experiments.

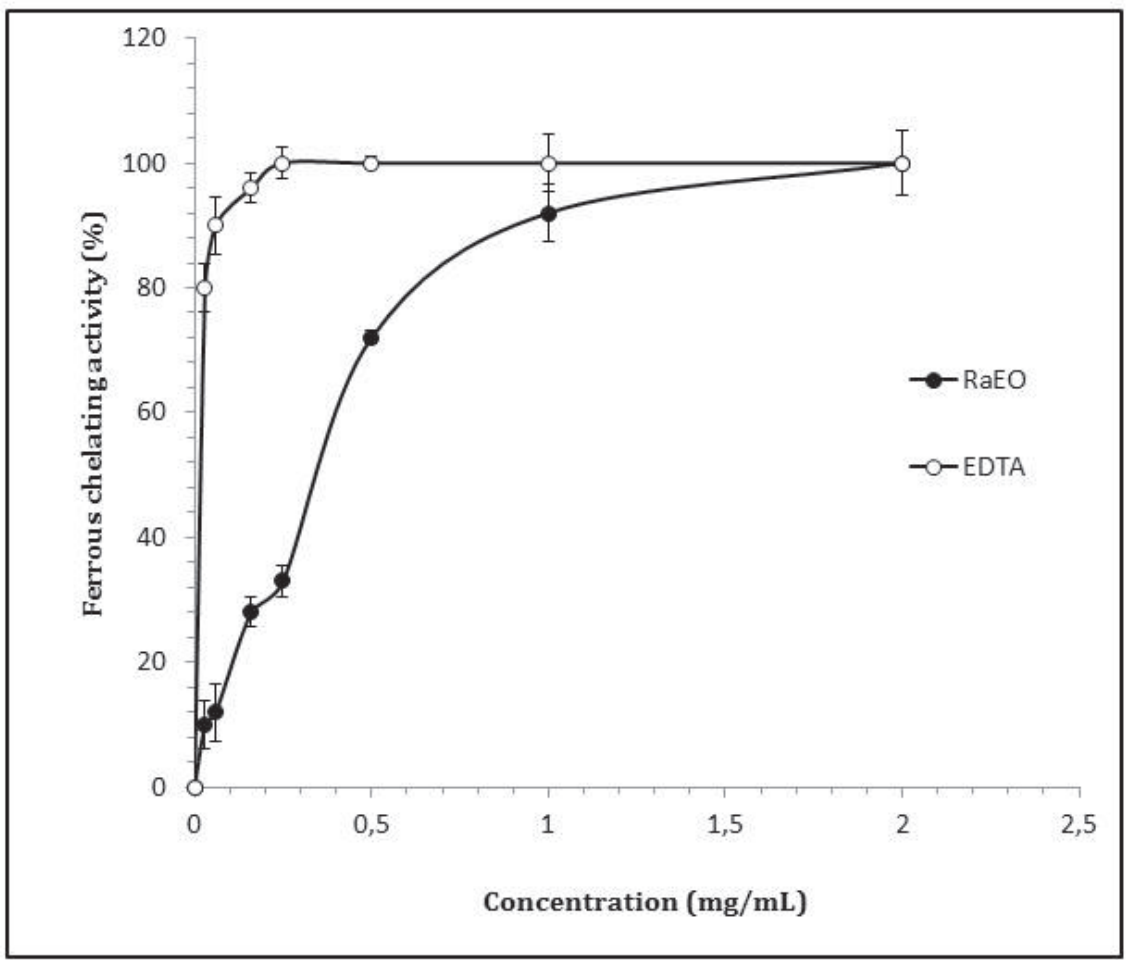

FIGURE 2 - Ferrous ions $\left(\mathrm{Fe}^{2+}\right)$ chelating activity of $\mathrm{RaEO}$ and standard antioxidant compound (EDTA). Data represent the mean $( \pm \mathrm{SD})$ of three independent experiments. 


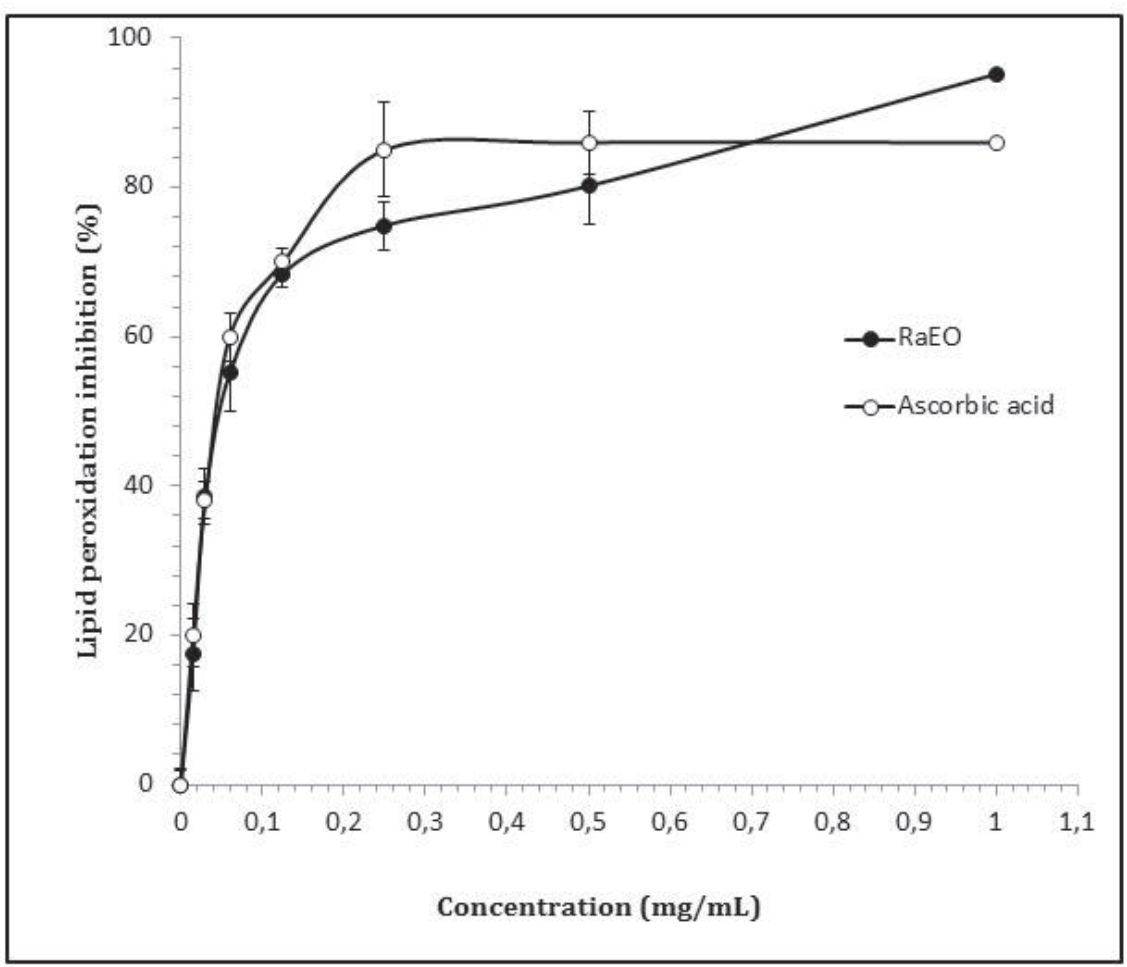

FIGURE 3 - Lipid peroxidation inhibition by RaEO using the TBARS method. Ascorbic acid was used as positive control. Data represent the mean $( \pm \mathrm{SD})$ of three independent experiments.

\section{Antimicrobial activity}

Data on the antimicrobial activity of RaEO, reported in this work for the first time, are given as inhibition zone (IZ) diameters, MICs, MBCs and MFCs (Table I). The antimicrobial activities of RaEO were evaluated using the agar diffusion and the microdilution methods against 12 test microorganisms, including 8 bacteria (two Gram-positive and six Gram-negative) and 4 yeasts. The RaEO was active against all the microbial strains, but in different degrees (Table I). The IZ varied from $11.67 \pm 0.58$ to $13.33 \pm 0.58 \mathrm{~mm}$, with MIC values ranging from 1.25 to $5.00 \mathrm{mg} / \mathrm{mL}$ for bacterial strains, and from $7.67 \pm 0.58 \mathrm{~mm}$ to $8.67 \pm$ $0.58 \mathrm{~mm}$ with MIC from $1.25 \mathrm{mg} / \mathrm{mL}$ to $5 \mathrm{mg} / \mathrm{mL}$ for yeast strains. As depicted in Table I, P. aeruginosa PAO1 was the most sensitive bacteria with IZ value of 13.33 $\pm 0.58 \mathrm{~mm}$, which is two-time larger than that obtained with ampicillin used as a positive control. According to the literature, the IZ measured in our study are much more important than those obtained by Boussaada et al. (2008) with the essential oil in the same species, but collected in different areas in Tunisia.
MBC or MFC are specified as the lowest concentration of essential oil or antibiotic at which inoculated bacteria or fungi are completely killed. As shown in Table I, these values varied from 5 to $10 \mathrm{mg}$ / $\mathrm{mL}$ for bacteria or yeasts. Again, the values of these two parameters (MBC or MFC) are different from those reported by Boussaada et al. (2008); this behavior can be explained by the differences in the chemical compositions of the two essential oils.

Being the most abundant component of the RaEO, germacrene $\mathrm{D}$ and $\beta$-caryophyllene, are known for their antimicrobial properties (Andrews, Parks, Spence, 1980; Cimanga et al., 2002; Burt, 2004; Bezic, Skocibusic, Dunkic, 2005). These compounds can increase the permeability of fungal cell and membrane fluidity and it can also prevent the acidification of medium. Furthermore, terpenes can induce change in cell permeability by entering between the fatty acyl chains of the membrane lipid bilayers (Sikkema, De Bont, Poolman, 1995; Christine, Brian, Thomas, 2002). However, since essential oil consists of various major and minor constituents, the synergistic effects of some compounds should be also taken into consideration. 
TABLE I - Antibacterial and antifungal activities (MIC, MBC and MFC in $\mathrm{mg} / \mathrm{mL}$ ) of RaEO

\begin{tabular}{|c|c|c|c|c|c|c|}
\hline \multirow{2}{*}{ Strains } & \multicolumn{3}{|c|}{ Essential oil } & \multicolumn{3}{|c|}{ Drug } \\
\hline & $\mathrm{IZ} \pm \mathrm{DS}$ & MIC & $\mathrm{MBC}$ & $\mathrm{IZ} \pm \mathrm{DS}$ & MIC & MBC \\
\hline Bacteria & & & & \multicolumn{3}{|c|}{ Ampicillin } \\
\hline Staphylococcus epidermidis CECT 231 & $12.67 \pm 0.58$ & 2.50 & 10.00 & $12.33 \pm 0.58$ & 5.00 & 10.00 \\
\hline Staphylococcus aureus ATCC 6816 & $13.00 \pm 01$ & 5.00 & 10.00 & $35.00 \pm 1$ & 0.30 & 5.00 \\
\hline Pseudomonas aeruginosa $\mathrm{PAO} 1$ & $13.33 \pm 0.58$ & 1.25 & 5.00 & $6.67 \pm 0.58$ & 1.25 & 5.00 \\
\hline Vibrio parahaemolyticus ATCC 43996 & $12.00 \pm 0.10$ & 1.25 & 5.00 & $11.67 \pm 0.58$ & 5.00 & 10.00 \\
\hline Salmonella enterica subsp. enterica CECT 443 & $11.67 \pm 0.58$ & 2.50 & 10.00 & $16.00 \pm 1$ & 2.50 & 10.00 \\
\hline Listeria monocytogenes CECT 933 & $11.67 \pm 0.58$ & 2.50 & 10.00 & $20.00 \pm 1$ & 1.25 & 5.00 \\
\hline Vibrio parahaemolyticus CECT 511 & $11.67 \pm 0.58$ & 5.00 & 10.00 & $17.00 \pm 1.73$ & 2.50 & 10.00 \\
\hline \multirow[t]{2}{*}{ Vibrio vulnificus CECT 529} & $13.00 \pm 01$ & 2.50 & 10.00 & $23.33 \pm 0.58$ & 1.25 & 5.00 \\
\hline & & & & $\mathrm{IZ} \pm \mathrm{DS}$ & MIC & MFC \\
\hline Yeasts & & & & \multicolumn{3}{|c|}{ Amphotericin B } \\
\hline Candida glabrata ATCC 90030 & $8.67 \pm 0.58$ & 1.25 & 5.00 & $10.33 \pm 1.15$ & 0.125 & 0.312 \\
\hline Candida albicans ATCC 2091 & $7.67 \pm 0.58$ & 5.00 & 10.00 & $11.33 \pm 0.57$ & 0.625 & 0.625 \\
\hline Candida parapsilosis ATCC 22019 & $7.67 \pm 0.58$ & 2.50 & 10.00 & $11.00 \pm 1$ & 0.625 & 1.25 \\
\hline Candida tropicalis 06-085 & $7.67 \pm 0.58$ & 2.50 & 10.00 & $10.33 \pm 1.15$ & 0.625 & 0.625 \\
\hline
\end{tabular}

IZ: Inhibition zone around the discs impregnated with RaEO (10 mg/mL), Ampicillin $(10 \mathrm{mg} / \mathrm{mL})$ or Amphotericin B (10 $\mathrm{mg} / \mathrm{mL}$ ) expressed as mean of three replicates $(\mathrm{mm} \pm \mathrm{SD})$.

SD: Standard deviation.

MIC: Minimal Inhibitory Concentration $(\mathrm{mg} / \mathrm{mL})$.

MBC: Minimal Bactericidal Concentration $(\mathrm{mg} / \mathrm{mL})$.

MFC: Minimal Fungicidal Concentration (mg/mL).

\section{Phytotoxic potential of the essential oil}

The phytotoxic effects of the tested essential oil are summarized in Table II. The allelopathic influence on Lactuca sativa L. seeds germination and seedlings growth varied according to the essential oil concentration. A significant inhibitory effect on the germination of L. sativa seeds was found (Table II). The germination percentage varied between 75 and $0 \%$ (values not reported in Table II) at the seventh day of germination. The RaEO showed very high phytotoxic effects against L. sativa, with an inhibition of seed germination of $100 \%$ at $0.25 \mathrm{mg} /$ $\mathrm{mL}$. Generally, essential oil exhibited germination and seedling growth inhibition that was concentrationdependent. Allelopathic effect was also obtained at the lowest concentration tested, $0.01 \mathrm{mg} / \mathrm{mL}(25 \%)$. The inhibition of the radical growth varied from 7.31 (at $0.01 \mathrm{mg} / \mathrm{mL}$ ) to $100 \%$ (at $0.25 \mathrm{mg} / \mathrm{mL}$ ) and that of the hypocotyl from 7.16 (at $0.01 \mathrm{mg} / \mathrm{mL}$ ) to $100 \%$ 
TABLE II - Allelopathic effects of RaEO on Lactuca sativa L. seedlings

Inhibitory effect compared to control (\%)

\begin{tabular}{lcccc}
$\begin{array}{l}\text { Concentration } \\
(\mathbf{m g} / \mathbf{m L})\end{array}$ & $\begin{array}{c}\text { Seed germination } \\
\text { (\% of control) }\end{array}$ & $\begin{array}{c}\text { Root lenght } \\
(\% \text { of control) }\end{array}$ & $\begin{array}{c}\text { Hypocotyl lenght } \\
\text { (\% of control) }\end{array}$ & $\begin{array}{c}\text { Seedling dry weight } \\
\text { (\% of control) }\end{array}$ \\
\hline 0.25 & $-100 \pm 0.0$ & $-100.0 \pm 0.0$ & $-100.0 \pm 0.0$ & $-100.0 \pm 0.0$ \\
0.1 & $-65 \pm 1.5$ & $-76.15 \pm 1.0$ & $-62.04 \pm 1.8$ & $-60.73 \pm 0.4$ \\
0.05 & $-35 \pm 1.3$ & $-26.63 \pm 1.2$ & $-18.01 \pm 1.03$ & $-46.55 \pm 0.3$ \\
0.01 & $-25 \pm 1.2$ & $-7.31 \pm 1.25$ & $-7.16 \pm 1.14$ & $-38.11 \pm 0.25$ \\
\hline
\end{tabular}

(at $0.25 \mathrm{mg} / \mathrm{mL}$ ). The highest activities were detected at $0.25 \mathrm{mg} / \mathrm{mL}$ concentration for the essential oil. The biomass production was slightly inhibited in the presence of the essential oil at $0.01 \mathrm{mg} / \mathrm{mL}$, and the dry weight of the seedlings treated with $0.25 \mathrm{mg} / \mathrm{mL}$ from sample was highly reduced (100\%).

The allelopathic effect is strongly related to the composition of essential oil and to the target species. The RaEO was efficient in inhibiting the seed germination and the seedling growth of L. sativa. The phytotoxic effect can be mainly due to toxic compounds identified in the essential oil (Boussaada et al., 2008). In line with our findings, few studies reported that some essential oils containing toxic compounds (e.g., limonene, caryophyllene oxide, spatulenol, etc.) also have interesting phytotoxic potentials (Chung, Ahn, Yun, 2001; Mabrouk et al., 2013). Furthermore, several researchers have shown that monoterpene compounds have strong inhibitory effects on seed germination of many crops and weeds. (Lopez, Bonzani, Zygadlo, 2009; Li et al., 2011). The bioassay results, reported here, demonstrated that the volatile oil of $R$. acaule possesses strong phytotoxic potential and could cause substantial germination reduction and seedling growth inhibition of L. sativa. Therefore, the decrease of the seed germination and the shoot length may be explained by the reduction of cell division rate and cell elongation due to the presence of the allelochemicals (Javaid, Anjum, 2006). Our findings indicate also that the inhibitory compounds present in Tunisian RaEO could be used as a potential natural herbicide resource.

\section{CONCLUSION}

The increasing interest of alternative and complementary medicine in the last decade shade light on essential oils, which represent a big class of plant secondary metabolites that possess diverse biological activity. For the $R$. acaule species, only a few studies were reported about its biological potentials. So, to the best of our knowledge, this is the first study to provide data on the antimicrobial and in vitro antioxidant activities of the essential oil obtained from aerial part of Tunisian $R$. acaule. From our results, the significant observed antioxidant and antibacterial effects of the RaEO may be due to the higher content of sesquiterpene hydrocarbons $(74.2 \%)$ without neglecting also minor compounds which may make a significant contribution to the oil activity. Finally, we have investigated, for the first time, the allelopathic activities of $R$. acaule essential oil on Lactuca sativa $L$. seeds germination and seedlings growth. The obtained allelopathic effect may be strongly related to some toxic compounds in this essential oil (e.g., limonene, caryophyllene, etc.) which have interesting phytotoxic potentials (Chung, Ahn, Yun, 2001; Mabrouk et al., 2013).

\section{ACKNOWLEDGMENTS}

The authors would like to thank all the colleagues who contributed to this work. The authors are indebted to Dr Anouar Fendri (Sfax University) for English language correction. 


\section{DISCLOSURE STATEMENT}

The authors declare that there are no conflicts of interest.

\section{REFERENCES}

Andrews RE, Parks LW, Spence KD. Some effects of Douglas fir terpenes on certain microorganisms. App Env Microbiol. 1980;40(2):301-304.

Bakkali F, Averbeck S, Averbeck D, Idaomar M. Biological effects of essential oils - A review. Food Chem Toxicol. 2008;46(2):446-475.

Bellé NAV, Dalmolin GD, Fonini G, Rubim MA, Rocha JBT. Polyamines reduces lipid peroxidation induced by different pro-oxidant agents. Brain Res. 2004;1008(2):245-251.

Bezic N, Skocibusic M, Dunkic V. Phytochemical composition and antimicrobial activity of Satureja montana L. and Satureja cuneifolia Ten. essential oils. Acta Bot Croat. 2005; 64(2):313-322.

Boussaada O, Ammar S, Saidana D, Chriaa J, Chraif I, Daami M, et al. Chemical composition and antimicrobial activity of volatile components from capitula and aerial parts of Rhaponticum acaule DC growing wild in Tunisia. J Microbiol Res. 2008;163(1):187-195.

Burt S. Essential oils: Their antibacterial properties and potential applications in Foods a review. Int J Food Microbiol. 2004;94(3):223-253.

Christine FC, Brian JM, Thomas VR. Mechanism of action of melaleuca alternifolia (Tea Tree) Oil on Staphylococcus aureus determined by time-kill, lysis, leakage, and salt tolerance assays and electron microscopy. Antimicrobiol Agent Chemother. 2002;46(6):1914-1920.

Cimanga K, Kambu K, Tona L, Apers S, De Bruyne T, Hermans N, et al. Correlation between chemical composition and antibacterial activity of essential oils of some aromatic medicinal plants growing in the Democratic Republic of Congo. J Ethnopharmacol. 2002;79(2):213-220.

Chung IM, Ahn JK, Yun SJ. Assessment of allelopathic potential of barnyard grass (Echinochloa crus-galli) on rice (Oryza sativa L.) cultivars. Crop Protection . 2001;20(10):921928.

Coppen PP. The Use of Antioxidants. In: Rancidity in Foods, Allen JC, Hamilton RJ (Eds.). London, New York:Applied Science Publisher; 1983.
Condelli N, Caruso MC, Galgano F, Russo D, Milella L, Favati F. Prediction of the antioxidant activity of extra virgin oils produced in the Mediterranean area. Food Chem. 2015;177:233-239.

Espin JC, Soler-Rivas C, Wichers HJ. Characterization of the total free radical scavenger capacity of vegetable oils and oil fractions using 2,2-diphenyl-1-picrylhydrazyl radical. J Agric Food Chem. 2000;48(3):648-56.

Hyun TK, Kim HC, Kim JS. Antioxidant and antidiabetic activity of Thymus quinquecostatus Celak. Ind Crop Prod. 2014;52:611-616.

Javaid A, Anjum T. Control of Parthenium hysterophorus L. by aqueous extracts of allelopathic grasses. Pak J Bot. 2006;38(1):139-145.

Kelen M, Tepe B. Chemical composition, antioxidant and antimicrobial properties of the essential oils of three Salvia species from Turkish flora. Bioresour Technol. 2008;99(10):4096-4104.

Kong Y, Xiao JJ, Meng SC, Dong XM, Ge YW, Wang RF et al. A new cytotoxic flavonoid from the fruit of Sinopodophyllum hexandrum. Fitoterapia. 2010;81(5):367-370.

Laciar A, Ruiz ML, Flores RC, Saad JR. Antibacterial and antioxidant activities of the essential oil of Artemisia echegarayi Hieron. (Asteraceae). Rev Argent Microbiol. 2009;41(4):226-231.

Li J, Liu X, Dong F, Xu J, Li Y, Shan W, et al. Potential allelopathic effects of volatile oils from Descurainia sophia (L.) Webb ex prantl on wheat. Biochem Syst Ecol. 2011;39(1):56-63.

López ML, Bonzani NE, Zygadlo JA. Allelopathic potential of Tagetes minuta terpenes by a chemical, anatomical, and phytotoxic approach. Biochem Syst Ecol. 2009;36(12):882890.

Mabrouk S, Bel Hadj Salah K, Elaissi A, Jlaiel L, Ben Jannet H, Aouni M, et al. Chemical composition and antimicrobial and allelopathic activity of Tunisian Conyza sumatrensis (Retz.) E.Walker essential oils. Chem Biodivers. 2013;10(2):209-223.

Maisuthisakul P, Suttajit M, Pongsawatmanit R. Assessment of phenolic content and free radical-scavenging capacity of some Thai indigenous plants. Food Chem. 2007;100(4):14091418.

Matasyoh JC, Kiplimo JJ, Karubiu NM, Hailstorks TP. Chemical composition and antimicrobial activity of essential oil of Tarchonanthus camphoratus. Food Chem. 2007;101(3):1183-1187. 
Mosbah H, Chahdoura H, Kammoun J, Hlila MB, Louati H, Hammami S, et al. Rhaponticum acaule (L) DC essential oil: Chemical composition, in vitro antioxidant and enzyme inhibition properties. BMC Complement Altern Med. 2018;18(1):79.

Parveen M, Ghalib RM, Khanam Z, Mehd, SH, Ali M. A novel antimicrobial agent from the leaves of Peltophorum vogelianum (Benth.). Nat Prod Res. 2010;24(13):1268-1273.

Pottier-Alapetite G. Flore de la Tunisie. AngiospermesDicotylédones Gamopétales. Publication Scientifiques Tunisiennes; 1981. p. 1070.

Priyadarsini KI, Maity DK, Naik GH, Kumar MS, Unnikrishnan MK, Satav JG, et al. Role of phenolic O-H and methylene hydrogen on the free radical reactions and antioxidant activity of curcumin. Free Radic Biol Med. 2003;35(5):475-484.

Ruberto G, Baratta MT. Antioxidant activity of selected essential oil components in two lipid model systems. Food Chem. 2000;69(2):167-174.

Sarikurkcu C, Tepe B, Semiz DK, Solak MH. Evaluation of metal concentration and antioxidant activity of three edible mushrooms from Mugla, Turkey. Food Chem Toxicol. 2010;48(5):1230-1233.

Silvério MS, Del-Vechio-Vieira G, Pinto MAO, Alves MS, Sousa OV. Chemical Composition and Biological Activities of Essential Oils of Eremanthus erythropappus (DC) McLeisch (Asteraceae). Molecules. 2013;18(8):9785-9796.

Sikkema J, De Bont JAM, Poolman B. Mechanisms of membrane toxicity of hydrocarbons. Microbiol. Rev. 1995;59(2):201-222.
Snoussi M, Noumi E, Trabelsi N, Flamini G, Papetti A, De Feo V. Mentha spicata essential oil: chemical composition: antioxidant and antibacterial activities against planktonic and biofilm cultures of Vibrio spp. strains. Molecules. 2015;20(8):14402-14424.

Sökmen A, Sökmen M, Daferera D, Polissiou M, Candan $\mathrm{F}$, Unlü $\mathrm{M}$, et al. The in vitro antioxidant and antimicrobial activities of the essential oil and methanol extracts of Achillea biebersteiniAfan. (Asteraceae). Phytother Res. 2004;18(6):451-456.

Thiansilakul Y, Benjakul S, Shahidi F. Compositions, functional properties and antioxidative activity of protein hydrolysates prepared from round scad (Decapterus maruadsi). Food Chem. 2007;103(4):1385-1394.

Vuddhakul V, Bhooponga P, Hayeebilana F, Subhadhirasakulb S. Inhibitory activity of Thai condiments on pandemic strain of Vibrio parahaemolyticus. Food Microbiol. 2007;24(4):413418.

Yayli N, Yaşar A, Güleç C, Usta A, Kolayli S, Coşkunçelebi $\mathrm{K}$, et al. Composition and antimicrobial activity of essential oils from Centaurea sessilis and Centaurea armena. Phytochemistry. 2005;66(14):1741-1745.

Zhang AH, Sun H, Wang XJ. Recent advances in natural products from plants for treatment of liver diseases. Eur J Med Chem. 2013;63:570-577.

Zhu L, Glahn RP, Yeung CK, Miller, DD. Iron uptake by Caco-2 cells from NaFeEDTA and FeSO4: Effects of ascorbic acid, $\mathrm{pH}$, and a $\mathrm{Fe}(\mathrm{II})$ chelating agent. J Agric Food Chem. 2006;54(20):7924-7928.

Received for publication on $22^{\text {nd }}$ June 2018 Accepted for publication on $30^{\text {th }}$ September 2018 